\title{
Iron(III) oxamato-catalyzed epoxidation of alkenes by dioxygen and pivalaldehyde
}

\author{
Rafael Ruiz, ${ }^{a}$ Maria Triannidis, ${ }^{a}$ Ally Aukauloo, ${ }^{a}$ Yves Journaux, ${ }^{* a}$ Isabel Fernández, ${ }^{b}$ José R. Pedro, ${ }^{* b}$ \\ Beatriz Cervera, ${ }^{c}$ Isabel Castro ${ }^{c}$ and M. Carmen Muñoz ${ }^{d}$ \\ a Laboratoire de Chimie Inorganique, URA 420, CNRS, Université de Paris-Sud, 91405 Orsay, France \\ ${ }^{b}$ Departament de Química Orgànica, Facultat de Química, Universitat de València, 46100 Burjassot, València, Spain \\ ${ }^{c}$ Departament de Química Inorgànica, Facultat de Química, Universitat de València, 46100 Burjassot, València, Spain \\ a Departamento de Física Aplicada, Universidad Politécnica de València, 46071 València, Spain
}

\begin{abstract}
A new iron(III)-carbonato monomeric complex of orthophenylenebis(oxamato) (opba) 1 is synthesized, and spectroscopically and structurally characterized; it is a moderately efficient non-heme catalyst for the aerobic epoxidation of alkenes with co-oxidation of pivalaldehyde.
\end{abstract}

There has been always a great interest in iron coordination chemistry owing to the relevant role that this transition metal ion plays in biology, particularly as the active metal center embedded in a large number of proteins involved in oxygen activation chemistry. ${ }^{1}$ Now, this interest is directed towards mono- and di-nuclear non-heme iron proteins, owing to the surprisingly diverse functional properties exhibited by them. ${ }^{2}$ Amido groups from asparagine or glutamine residues in the polypeptide backbone of some of these mononuclear iron proteins are frequently shown to coordinate to the iron metal center through their oxygen donor atom, like in lipid dioxygenase and isopenicillin $N$-synthase. ${ }^{2 a}$ Moreover, amido nitrogen coordination has been invoked in bleomycin, a natural ironcontaining glycopeptide with antibiotic and antitumor properties of fundamental importance in medicine. ${ }^{2 a}$ That being so, it is evident that knowledge of the chemistry and reactivity properties of iron-amido complexes becomes particularly appropriate in order to understand the key steps of the enzymatic mechanism proposed for this class of non-heme iron proteins and antibiotics. Since the review of Sigel and Martin devoted to the coordinating properties of the amide bond with copper, nickel, cobalt and zinc metal ions, ${ }^{3}$ a considerable effort has been made in the last fifteen years in order to detect iron ion interactions with the amide group. ${ }^{4-6}$ Recently, we have initiated an investigation program to assess the possible use of bis-N-substituted oxamato ligands like ortho-phenylenebis(oxamato) (opba) in the stabilization of unusual high oxidation state transition metal ions due to the high donor capacity of the deprotonated-amido group. ${ }^{7}$ We report here on the synthesis and physical characterization, $\dagger$ and the crystal and molecular structure $\$$ of its corresponding oxamato iron(III) complex of formula $\left[\mathrm{NMe}_{4}\right]_{3}\left[\mathrm{Fe}(\mathrm{opba})\left(\mathrm{CO}_{3}\right)\right] \cdot 5 \mathrm{H}_{2} \mathrm{O} \quad \mathbf{1}$, as well as its activity toward alkene epoxidation with dioxygen.

Complex 1 consists of mononuclear $\left[\mathrm{Fe}(\text { opba })\left(\mathrm{CO}_{3}\right)\right]^{3-}$ complex anions (Fig. 1), tetramethylammonium cations and crystallization water molecules. The iron atom is bound to the two deprotonated amido nitrogens and two carboxylate oxygens of the opba ligand and to two oxygen atoms from the carbonate in a rhombically distorted octahedral coordination geometry. The carbonate chelating group is symmetrically bound to the metal $(2.034,2.045 \AA$ for $\mathrm{Fe}-\mathrm{O})$ occupying two cis positions of the octahedron with a typical small bite angle $\left[63.2^{\circ}\right.$ for $\mathrm{O}(7)-\mathrm{Fe}-\mathrm{O}(8)]$. This imposes a non-planar conformation for the tetradentate opba ligand which is the only compatible with an octahedral environment at the metal ion. In fact, the opba ligand adopts a cis- $\beta$ geometry with the $\mathrm{N}(1), \mathrm{N}(2)$ and $\mathrm{O}(2)$ donor atoms occupying three meridional positions around iron. This situation contrasts to previous descriptions of mononuclear complexes with this ligand or its derivatives in which all four donor atoms form a plane (trans geometry). ${ }^{7,8}$ The distortion from planarity of the opba ligand is accommodated by a disrotatory rotation of the $\mathrm{C}(3)-\mathrm{N}(2)$ amide bond defined as the angle between the $\mathrm{C}(6) \mathrm{C}(3) \mathrm{N}(2)$ and $\mathrm{C}(3) \mathrm{N}(2) \mathrm{C}(4)$ mean planes [17 $c f .2^{\circ}$ for the equivalent $\mathrm{C}(1)-\mathrm{N}(1)$ amide bond], as previously observed in a related cobalt(III) diamido$N$-dialkoxido complex. ${ }^{9}$ This distortion is also reflected in the metal-ligand bond lengths, with a significant difference between the two $\mathrm{Fe}-\mathrm{O}$ (carboxylate) bond distances of $\mathrm{ca} .0 .05$ $\AA$, the longer $\mathrm{Fe}-\mathrm{O}(5)$ distance being trans to that of the carbonate ligand $\mathrm{Fe}-\mathrm{O}(8)$ which is the longest bond of the octahedron. The $\mathrm{Fe}-\mathrm{N}$ (amide) bond distances average $2.05 \AA$, a value very close to that observed in high-spin iron(III) complexes containing amido nitrogen bonds, 5 but significantly longer than those of the analogous intermediate ${ }^{4 b}$ or low-spin 6 iron(III)-amide bonds (1.93-1.96 ̊).

In order to uncover the potential reactivity of this new iron(III) complex, we have examined its ability to catalyse the epoxidation of some representative disubstituted alkenes using dioxygen as oxidant in the presence of an aldehyde. ${ }^{10}$ The

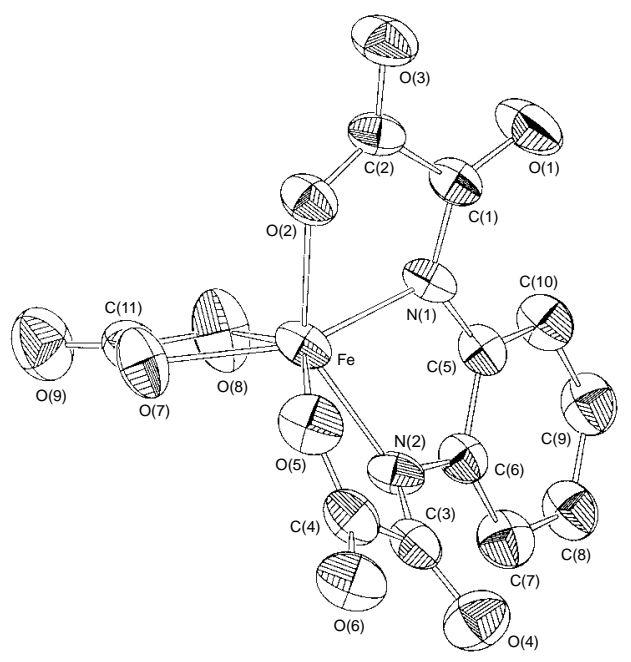

Fig. 1 Perspective view of the anionic mononuclear unit of 1 with the atom numbering scheme (thermal ellipsoids are at the $30 \%$ probability level and hydrogen atoms have been omitted for clarity). Selected bond distances ( $\mathrm{A})$ and angles $\left({ }^{\circ}\right)$ with standard deviations in parentheses: $\mathrm{Fe}-\mathrm{N}(1) 2.048(5)$, $\mathrm{Fe}-\mathrm{N}(2) 2.045(6), \mathrm{Fe}-\mathrm{O}(2) 1.986(4), \mathrm{Fe}-\mathrm{O}(5)$ 2.035(4), $\mathrm{Fe}-\mathrm{O}(7)$ 2.034(5), $\mathrm{Fe}-\mathrm{O}(8)$ 2.045(5); N(1)-Fe-N(2) 75.9(2), N(1)-Fe-O(2) 78.5(2), N(1)-Fe$\mathrm{O}(5)$ 125.5(2), N(1)-Fe-O(7) 147.4(2), N(1)-Fe-O(8) 86.9(2), N(2)-Fe$\mathrm{O}(2)$ 142.8(2), N(2)-Fe-O(5) 77.9(2), N(2)-Fe-O(7) 118.9(2), N(2)-Fe$\mathrm{O}(8)$ 98.9(3), O(2)-Fe-O(5) 96.0(2), O(2)-Fe-O(7) 97.1(2), O(2)-Fe-O(8) 106.2(2), O(5)-Fe-O(7) 86.9(2), O(5)-Fe-O(8) 144.2(2), O(7)-Fe-O(8) 63.2(2). 
Table 1 Results for the epoxidation of alkenes by dioxygen and pivalaldehyde catalyzed by $\mathbf{1}^{a}$

\begin{tabular}{llll}
\hline Entry & Alkene & $t / \mathrm{h}$ & Yield $^{b, c}(\%)$ \\
\hline 1 & trans-Stilbene & 3 & 95 \\
2 & cis-Stilbene & $3^{d}$ & 15 \\
3 & Cyclohexene & 4 & 45 \\
4 & 1,2-Dihydronaphthalene & 4 & 50 \\
5 & 1,2-Dihydronaphthalene & 4 & 80 \\
\hline
\end{tabular}

${ }^{a}$ Reactions were carried out at room temperature by adding a fluorobenzene solution $(0.2 \mathrm{ml})$ of the alkene $(0.11 \mathrm{mmol})$ to a stirred mixture of the metal catalyst $\left(6.5 \times 10^{-3} \mathrm{mmol}\right)$ and pivalaldehyde $(0.33 \mathrm{mmol})$ in fluorobenzene $(0.2 \mathrm{ml})$ under dioxygen atmosphere. The consumption of the alkene and the formation of the corresponding epoxide during the course of the reaction were monitored by TLC. The obtained epoxide and the unreacted alkene were separated by flash column chromatography on silica gel. ${ }^{b}$ Yields refer to isolated and pure compounds (column chromatography on silica gel). All compounds exhibited spectral data consistent with their structures. ${ }^{c}$ In the absence of catalyst some extension of epoxidation was observed. ${ }^{d}$ With a reaction time of $24 \mathrm{~h}$ the final conversion was almost identical (ca. 20\%). ${ }^{e}$ In the presence of $N$-methylimidazole $(0.11 \mathrm{mmol})$.

results are summarized in Table 1 . Complex $\mathbf{1}$ catalyses the epoxidation of trans-stilbene by dioxygen plus pivalaldehyde in fluorobenzene solution with yields as high as $95 \%$ of the corresponding epoxide, trans-stilbene oxide, after $3 \mathrm{~h}$ (entry 1 ). By contrast, the percent conversion in the case of cis-stilbene is of only $15-20 \%$ even after a total reaction time of $24 \mathrm{~h}$ (entry 2 ), indicating that the catalytic epoxidation is greatly stereodependent. For both $c i s$ - and trans-stilbene, however, epoxides were the only oxidation products as confirmed by ${ }^{1} \mathrm{H}$ NMR spectroscopy. As a matter of fact, no trace of the corresponding ketone or alcohol were detected for the epoxidation of cyclohexene which is typically regarded as a good substrate to check for competition of alkene epoxidation $v s$. allylic oxidation (entry 3 ). This observation suggests that typical free radical intermediates are not directly involved as potential epoxidizing agents. On the other hand, it is noteworthy that the amount of epoxide obtained with $\mathbf{1}$ increases in the presence of $N$-methylimidazole: for instance, almost a twofold yield enhancement was found for the epoxidation of 1,2-dihydronaphthalene, i.e. from 50 to $80 \%$ after $4 \mathrm{~h}$ (entries 4 and 5, respectively). Although it is premature to discuss the precise mechanism at the present stage, $N$-methylimidazole most likely acts as a monodentate donor ligand toward the iron(III) ion by replacement of the bidentate carbonate ligand, and thereby affording a vacant coordination site on the iron center for reaction with the potential oxidant. Furthermore, even if the exact role of the metal complex in the epoxidation of alkenes by dioxygen with co-oxidation of aldehydes is still unclear, recent studies by Valentine and coworkers ${ }^{11}$ demonstrate that it coordinates to the acylperoxy radicals generated in the autooxidation of the aldehyde forming a metal-acylperoxo complex. That being so, iron(IV)-acylperoxo or iron(v)-oxo species derived by oxygen-oxygen bond cleavage of the acylperoxo group, seem to us the more probable candidates to play the role of active epoxidizing agents in our system. In this regard, it is interesting to note that Collins et al. have isolated stable iron(IV) complexes with amido-containing ligands which would be a model for the proposed catalytic entities in our oxidation system. ${ }^{4 a}$ Attempts to characterize these reactive intermediates species using other transition metal ions with more accessible high-valent oxidation states such as manganese are in progress in our laboratory.

This work was supported by the DGICYT, Ministerio de Educación y Ciencia (Spain) through projects PB94-0985 and PB94-1002. We acknowledge the financial support of the group Rhône-Poulenc. R. R. and B. C. thank the Ministerio de Educación y Ciencia (Spain) and the Conselleria de Educació i Ciència de la Generalitat Valenciana (Spain) for grants. We would also like to express our gratitude to Dr J. J. Girerd and Dr P. Mialane for fruitful discussions.

\section{Footnotes and References}

* E-mail: jour@icmo.u-psud.fr

$\dagger$ Syntheses and selected data for 1: A solution of the diethyl ester derivative of opba $(1.54 \mathrm{~g}, 5 \mathrm{mmol})$ in methanol $(100 \mathrm{ml})$ was charged with a $25 \%$ methanol solution of $\mathrm{NMe}_{4} \mathrm{OH}\left(10 \mathrm{~cm}^{3}, 25 \mathrm{mmol}\right)$ and the resulting mixture was stirred at $60{ }^{\circ} \mathrm{C}$ for $15 \mathrm{~min}$ in order to facilitate the hydrolysis of the ethyl ester groups. A methanolic solution $(50 \mathrm{ml})$ of iron(III) perchlorate hydrate $(1.77 \mathrm{~g}, 5 \mathrm{mmol})$ was then added dropwise via a dropping funnel under stirring. The resulting intensely red coloured solution was filtered to eliminate the white precipitate of $\mathrm{NMe}_{4} \mathrm{ClO}_{4}$, and reduced to a final volume of $10 \mathrm{ml}$ on a rotatory evaporator. The concentrated solution was treated successively with diethyl ether and acetone to give a very hygroscopic product (solid or oil) which was recuperated with acetonitrile $(300 \mathrm{ml})$. The suspension obtained was gently heated for $5 \mathrm{~h}$ with vigorous stirring and then filtered to eliminate the remainder of the solid particles. Upon standing at room temperature, a first crop of a side product appeared which was also filtered and separated from the mother-liquor. Slow evaporation of the filtered solution in air afforded, after 2 weeks, red needles of $\mathbf{1}$ in small amounts which were picked by hand, dried on filter paper and stored under vacuum owing to its hygroscopic character. The crystals so obtained were suitable for X-ray diffraction. Satisfactory elemental analyses were obtained (C, H, N, Fe). $v_{\max } / \mathrm{cm}^{-1}(\mathrm{KBr}) 1660 \mathrm{~s}(\mathrm{sh}), 1635 \mathrm{vs}(\mathrm{br})$ and $1571 \mathrm{~s}(\mathrm{CO})$ (opba ligand and $\mathrm{CO}_{3}{ }^{2-}$ ) and 950s (NC) from $\mathrm{NMe}_{4}{ }^{+}$. UV-VIS (MeCN) $\left.\lambda_{\text {max }} / \mathrm{nm}_{\varepsilon}\left[\varepsilon \mathrm{dm}^{3} \mathrm{~mol}^{-1} \mathrm{~cm}^{-1}\right)\right] 221\left(4.0 \times 10^{4}\right), 257\left(4.2 \times 10^{4}\right), 264(\mathrm{sh})$, $308\left(3.0 \times 10^{4}\right), 408\left(2.7 \times 10^{3}\right)$. Magnetic moment (room temp.): $5.9 \mu_{\mathrm{B}}$. EPR spectrum (X-band, powder sample, liquid- $\mathrm{N}_{2}$ temperature): a strong feature at $g_{\text {eff }}=4.3$ which typically arises in a completely rhombic system $(E / D=1 / 3)$ for $D>0.23 \mathrm{~cm}^{-1}$

$\$ X$-Ray crystal structure analysis: Enraf-Nonius CAD-4 diffractometer, Mo-K $\alpha$ radiation, $\lambda=0.71069 \AA$, graphite monochromator, $293 \mathrm{~K}$. Lorentz and polarization effects but not absorption correction $(\mu=9.26$ $\mathrm{cm}^{-1}$ ). Data collection, solution and refinement: $\omega-\theta$, standard Patterson methods with subsequent full-matrix least-squares method refinement. SHELX86, SHELX93. ${ }^{12} \mathrm{C}_{23} \mathrm{H}_{50} \mathrm{FeN}_{5} \mathrm{O}_{14}$, monoclinic, space group $P 2{ }_{1} / a$, $a=11.441(2), b=17.496(2), c=17.047(2) \AA, \beta=104.52(2)^{\circ}$, $U=3303(1) \AA^{3}, Z=4, D_{\mathrm{c}}=1.36 \mathrm{~g} \mathrm{~cm}^{-3}, 1 \leqslant \theta \leqslant 25^{\circ}$, crystal size 0.15 $\times 0.10 \times 0.05 \mathrm{~mm} .4456$ unique reflections with 3362 assumed as observed with $I \geqslant 2 \sigma(I)$. The hydrogen atoms were located from a difference synthesis and refined with an overall isotropic thermal parameter. Refinement on $F^{2}$ of 390 variables with anisotropic thermal parameters for all non-hydrogen atoms gave $R=0.079$ and $R_{\mathrm{w}}=0.108$ with $S=1.8$ (observed data). CCDC 182/628.

1 Active Oxygen in Biochemistry, ed. J. S. Valentine, C. S. Foote, A. Greenberg and J. F. Liebman, Chapman and Hall, London, 1995.

2 (a) A. L. Nivorozhkin and J. J. Girerd, Angew. Chem., Int. Ed. Engl., 1996, 35, 609 and references therein; (b) L. Que, Jr. and Y. Dong, Acc. Chem. Res., 1996, 29, 190.

3 H. Sigel and R. B. Martin, Chem. Rev., 1982, 82, 385.

4 (a) T. J. Collins, K. L. Kostka, E. Münck and E. Uffelman, J. Am. Chem. Soc., 1990, 112, 5637; (b) K. L. Kostka, B. G. Fox, M. P. Hendrich, T. J. Collins, C. E. F. Rickard, L. J. Wright, E. Münck, J. Am. Chem. Soc., 1993, 115, 6746.

5 Y. Yang, F. Diederich and J. S. Valentine, J. Am. Chem. Soc., 1991, 113, 7195.

6 X. Tao, D. W. Stephan and P. K. Mascharak, Inorg. Chem., 1987, 26, 754

7 R. Ruiz, C. Surville-Barland, A. Aukauloo, E. Anxolabehere-Mallart, Y. Journaux, J. Cano and M. C. Muñoz, J. Chem. Soc., Dalton Trans., 1997, 745.

8 M. Tettouhi, L. Ouahab, A. Boukhari, O. Cador, C. Mathoniere and O. Kahn, Inorg. Chem., 1996, 35, 4932.

9 T. J. Collins and J. M. Workman, Angew. Chem., Int. Ed. Engl., 1989, 28, 912.

10 J. Estrada, I. Fernandez, J. R. Pedro, X. Ottenwaelder, R. Ruiz and Y. Journaux, Tetrahedron Lett., 1997, 38, 2377.

11 W. Nam, H. J. Kim, S. H. Kim, R. Y. N. Ho and J. S. Valentine, Inorg. Chem., 1996, 35, 1045 and references therein.

12 G. M. Sheldrick, SHELX. A Program for Crystal Structure Determination, University of Göttingen, DFR, 1986; G. M. Sheldrick, SHELXL93. Program for the Refinement of Crystal Structures, University of Göttingen, 1993.

Received in Basel, Switzerland, 7th August 1997; 7/05787C 